\title{
DESAFIOS NA IMPLEMENTAÇÃO DA LEI MARIA DA PENHA
}

\author{
Carmen Hein de Campos
}

CHALLENGES TO THE IMPLEMENTATION OF THE MARIA DA PENHA LAW

\section{RESUMO}

ESTE ARTIGO DISCUTE A SITUAÇÃO DAS PRINCIPAIS INSTITUIC̄ÕES QUE COMPÕEM A REDE ESPECIALIZADA DE ATENDIMENTO À MULHER EM SITUAÇĀO DE VIOLÊNCIA E SEU IMPACTO SOBRE A IMPLEMENTAÇÃO DA LEI MARIA DA PENHA. PARTINdo do trabalho da Comissão Parlamentar QUE INVESTIGOU A VIOLÊNCIA CONTRA A MULHER, O ARTIGO AMPLIA AS REFLEXÕES EXISTENTES SOBRE OS SERVIÇOS, APONTANDO OS PRINCIPAIS OBSTÁCULOS E OS NOVOS DESAFIOS PARA O REFORÇO DA DIMENSÃO PREVENTIVA E ASSISTENCIAL PROPOSTA PELA LEI.

\section{PALAVRAS-CHAVE}

Lei Maria da Penha; Comissão Parlamentar de INQUÉRITO; REDE DE ASSISTÊNCIA.

\begin{abstract}
THIS ARTICLE ANALYSIS THE SPECIALIZED NETWORK INSTITUTIONS FOR DOMESTIC VIOLENCE AGAINST WOMEN AND ITS IMPACT ON THE IMPLEMENTATION of the Maria da PENHA LAW. BASED on tHE WORK of the PARLIAMENTARY COMMISSION THAT INVESTIGATED VIOLENCE AGAINST WOMEN, THE ARTICLE WIDENS THE EXISTING REFLECTIONS ON SERVICES, POINTING OUT THE MAIN OBSTACLES AND NEW CHALLENGES TO STRENGTHEN THE PREVENTIVE DIMENSION PROPOSED BY THE LAW.
\end{abstract}

\section{KEYWORDS}

Maria da Penha LaW; Comission of Inquery; SPECIALIZED NETWORK.

\section{INTRODUÇÃO}

A Lei Maria da Penha (Lei n. 11.340/2006) é uma experiência bem-sucedida de advocacy feminista (BARSTED, 2011). Dentre suas principais características destacamse a perspectiva da complexidade da violência doméstica e familiar visualizada pelo tratamento integral, multidisciplinar e em rede; a tutela penal exclusiva para as mulheres e a criação da categoria normativa de violência de gênero; as definições de violência para além dos tipos penais tradicionais (violência física e ameaça); a unificação dos procedimentos judiciais cíveis e criminais em um mesmo juizado em virtude de 
um único fato gerador - a violência - evitando-se que a mulher tenha de percorrer duas instâncias judiciais; as medidas protetivas de urgência que objetivam oferecer um mecanismo rápido de contenção da violência sem necessariamente instaurar um inquérito policial; as medidas extrapenais, de natureza preventiva, que pretendem intervir no contexto cultural para mudar as noções estereotipadas de gênero; a redefinição da expressão "vítima” (CAMPOS; CARVALHO, 2011).

Estas, dentre outras inovações jurídicas introduzidas pela Lei Maria da Penha, provocaram inúmeros debates e resistências à sua aplicação (CAMPOS; CARVALHO, 2011; PASINATO, 2011; 2015).

Após 8 anos de vigência, persistem desafios para que a lei consiga cumprir seus objetivos e ter sua aplicação segundo as suas prescrições, conforme identificou a Comissão Parlamentar Mista de Inquérito (CPMI). O objetivo deste artigo é analisar os principais obstáculos encontrados pela CPMI na implementação da Lei Maria da Penha, especialmente no que respeita à rede especializada de atendimento. A maioria dos estudos produzidos sobre a rede especializada após a edição da LMP está dirigida à análise das Delegacias da Mulher (DEAMs) e dos Juizados Especializados (OBSERVE, 2010; 2011; PASINATO, 2011; CEPIA, 2013). Poucos estudos analisaram outros serviços como centros de referência (MADSEN; ABREU, 2014; SANTOS, 2015) e, ainda, Departamentos Médico-Legais (DML), serviços de abortamento, casas-abrigo, dentre outros. A partir do trabalho da CPMI, do qual tive a oportunidade de participar, sistematizo os seus principais achados, cotejando-os com estudos já realizados sobre o tema. Embora a CMPI não tenha descoberto "a roda”, o seu mérito está em traçar um panorama da rede de atendimento em todo o País, ampliando os estudos e as pesquisas realizados em localidades específicas. Assim, este artigo discute a situação das principais instituições que compõem a rede especializada de atendimento à mulher em situação de violência e reflete seu impacto sobre a implementação da Lei Maria da Penha.

\section{i A CPMi, a lei Maria da Penha e a rede especializada de ATENDIMENTO}

A Comissão Parlamentar Mista de Inquérito (CPMI) da Violência contra a Mulher, do Congresso Nacional, entre março de 2012 e julho de 2013, investigou a violência contra as mulheres no País. ${ }^{1}$ O conjunto deste trabalho está reunido no Relatório Final (2013) cujas conclusões corroboram o que estudos e práticas feministas já apontavam: a falta de prioridade política no enfrentamento à violência contra as mulheres (PASINATO, 2011; OBSERVE, 2010) e as maiores dificuldades enfrentadas por grupos de mulheres mais vulneráveis, tais como negras (MADSEN; ABREU, 2014), quilombolas, ribeirinhas, indígenas etc., a pouca articulação da rede especializada (PASINATO, 2011; 2015; SANTOS, 2015; CEPIA, 2013) e, acredito, um possível esgotamento de alguma dessas políticas públicas. 
A Lei Maria da Penha (LMP) é o principal instrumento legal para a proteção das mulheres em situação de violência doméstica e familiar. Ao instituir uma política pública e um sistema de medidas de assistência e proteção às mulheres em situação de violência por meio de um conjunto articulado de ações da União, dos Estados, do Distrito Federal, dos Municípios e organizações não governamentais, ${ }^{2}$ a sua implementação depende de políticas de prevenção e assistência, do comprometimento dos agentes públicos e da articulação de toda a rede ${ }^{3}$ (PASINATO, 2015). No entanto, algumas dessas respostas parecem já não dar conta da complexidade do mundo contemporâneo e da vida das mulheres. No entanto, a ausência de serviços em vários cantos do País parece contradizer essa afirmação, pois não pode haver esgotamento de uma política se sequer ela existiu plenamente. Assim, a complexidade da situação requer cautela na análise, pois, se pode haver um afastamento das mulheres de alguns serviços da rede nas capitais, o mesmo não acontece no interior do País, onde sequer há o acesso à rede. Dessa forma, a diversidade das situações de vida das mulheres, a heterogeneidade das perspectivas das redes (SANTOS, 2015) e a diversidade geográfica do Brasil não permitem uma conclusão generalizadora.

A política nacional de enfrentamento à violência contra a mulher é desenvolvida pela Secretaria de Políticas para as Mulheres da Presidência da República (SPM/PR) em parceria com estados e municípios. Essa política é constituída por inúmeras ações estabelecidas no Pacto Nacional de Enfrentamento à Violência contra a Mulher (BRASIL, 2011, p. 14-15). Um dos eixos do pacto é a ampliação e fortalecimento da rede de serviços para mulheres em situação de violência.

Conforme a SPM/PR, a rede de serviços para mulheres em situação de violência (rede especializada) é constituída por Centros de Atendimento à Mulher em situação de violência (Centros de Referência de Atendimento à Mulher, Núcleos de Atendimento à Mulher em situação de Violência, Centros Integrados da Mulher), Casas-abrigo, Casas de Acolhimento Provisório (Casas de Passagem), Delegacias Especializadas de Atendimento à Mulher (postos ou seções da Polícia de Atendimento à Mulher), Núcleos da Mulher nas Defensorias Públicas, Promotorias Especializadas, Juizados Especiais de Violência Doméstica e Familiar contra a Mulher, Central de Atendimento à Mulher Ligue 180, Ouvidoria da Mulher, Serviços de saúde voltados para o atendimento aos casos de violência sexual e doméstica, Posto de Atendimento Humanizado nos aeroportos (tráfico de pessoas) e Núcleo de Atendimento à Mulher nos serviços de apoio ao migrante (BRASIL, 2011, p. 15).

Como se observa, uma série de serviços de diferentes setores compõe a rede de assistência, tais como assistência social, segurança pública, saúde e justiça. Dessa forma, a rede especializada de serviços integra a rede mais ampla de enfrentamento à violência contra a mulher, duas perspectivas divididas entre gestão/formulação e execução, mas unidas pela interdisciplinaridade, intersetorialidade e transversalidade de gênero (PASINATO, 2015). Conforme Pasinato (2015, p. 537), a rede de enfrentamento 
articula, projeta, formula, programa, implanta, monitora e avalia, enquanto que a rede de atendimento executa, implanta, aplica, atende e encaminha. Durante as visitas da CPMI, foi possível observar o atendimento propriamente dito, a execução e o encaminhamento.

A CPMI verificou ainda que a rede de atendimento é reduzida se considerarmos a diversidade regional e especialmente a dimensão geográfica do País, fato também constatado por outras pesquisas (OBSERVE, 2011). O Brasil possui 26 estados, um Distrito Federal e 5.570 municípios (IBGE, 2013) e a rede especializada de atendimento é composta de 977 serviços, o que significa que atinge menos de 20\% dos municípios brasileiros (BRASIL, 2013).

Além disso, as verbas concentram-se nas capitais e os municípios menores possuem poucos recursos para a execução das políticas públicas. No entanto, muitos não têm a compreensão sobre o tema e não relacionam os problemas estruturais, tais como a falta de água, de esgoto, de escolas etc., a situações que podem tornar mais vulneráveis determinadas populações, especialmente, mulheres.

No entanto, é importante pontuar que desde 2003 a SPM/PR vem investindo na ampliação dos serviços e estes cresceram significativamente desde então, conforme se observa no Quadro 1.

QUADRO 1: EVOLUÇÃO DOS SERVIÇOS ESPECIALIZADOS

SERVIC̣OS

ANOS

\begin{tabular}{llll}
\hline & 2003 & 2007 & 2011 \\
\hline CENTROS DE REFERÊNCIA & 36 & 110 & 187 \\
\hline CASAS-ABRIGO & 43 & 63 & 72 \\
\hline DEFENSORIA ESPECIALIZADA & 4 & 24 & 57 \\
\hline JUIZADOS E VARAS ADAPTADAS & 248 & 338 & $470^{*}$ \\
\hline PROMOTORIA ESPECIALIZADA/NÚCLEO DE GÊNERO MP & 0 & 47 & 48 \\
\hline TOTAL & 0 & 7 & 928 \\
\hline
\end{tabular}

Fonte: Secretaria de Políticas para as Mulheres.

* O número inclui os postos de atendimento à mulher. 
Em 2013, conforme o Relatório da CPMI, o número de serviços continuou crescendo.

QUAdro 2: REDE ESPECIALIZADA DE ATENDiMENTO À MULHER

SERVIC̣OS

NÚMERO

\begin{tabular}{lr}
\hline DEAMS & $408^{*}$ \\
\hline NÚCLEOS ESPECIALIZADOS EM DELEGACIAS COMUNS & 103 \\
\hline CENTROS DE REFERÊNCIA & 202 \\
\hline CASAS-ABRIGO & 71 \\
\hline JUIZADOS ESPECIALIZADOS DE VIOLÊNCIA DOMÉSTICA & 66 \\
\hline VARAS ADAPTADAS & 27 \\
\hline PROMOTORIAS DA MULHER & 64 \\
\hline DEFENSORIAS OU NÚCLEOS DE DEFESA DA MULHER & 36 \\
\hline TOTAL & 977 \\
\hline
\end{tabular}

Fonte: CMPI da Violência contra a Mulher.

* Somando-se o número das DEAMs com os Postos de Atendimento tem-se 551, um aumento de 41 unidades.

Entretanto, a maioria desses serviços encontra-se nas capitais e regiões metropolitanas, o que dificulta o acesso das mulheres que moram em bairros afastados ou mesmo em regiões distantes, como na zona da mata, rural, floresta etc.

Além disso, a falta de articulação entre os diversos serviços da rede é outro obstáculo ao acesso aos serviços (OBSERVE, 2010, PASINATO, 2011; 2015; SANTOS, 2015). A CPMI averiguou que muitos serviços não se comunicam entre si, mesmo estando no mesmo prédio ou situados proximamente, ou ainda pertencentes à mesma instituição, como as delegacias e os serviços médico-legais, em geral, vinculados às secretarias de segurança. A falta de articulação impede o oferecimento de outros serviços às mulheres, a complementariedade, transversalidade da atuação, resultando em prejuízo às mulheres (BRASIL, 2013, p. 47; PASINATO, 2015). Assim, a falta de articulação faz com que alguns serviços sejam pouco acessados pelas mulheres e, dessa forma, considerados desnecessários ou ociosos por alguns gestores. Para Santos (2015), 
essa falta de articulação ou de conhecimento recíproco entre as redes é uma "falta de linha” (SANTOS, 2015, p. 580), cuja diferença nas abordagens ou na comunicação das redes pode ser explicada pelos seguintes fatores: a) a posição institucional de cada serviço; b) a formação profissional e extracurricular das/os agentes institucionais; c) a história do serviço.

Em vários estados, sequer pode-se dizer que constituem uma rede, pois não conversam entre si, não discutem casos coletivamente, não pensam em conjunto a resolução dos problemas etc. Cada serviço age individualmente e não institucionalmente articulado (BRASIL, 2013; SANTOS, 2015; PASINATO, 2015). A ação isolada ou precariamente conjugada dificulta o acesso das mulheres e, consequentemente, a implementação da Lei Maria da Penha.

A seguir, analisa-se o funcionamento de cada serviço que compõe a rede a partir das constatações da Comissão e de pesquisas sobre o tema.

\section{I Delegacias Especializadas de Atendimento à Mulher (DEAMs)}

Surgidas na década de 1980, em pleno processo de redemocratização do País, as Delegacias da Mulher foram uma resposta governamental às denúncias feministas de descaso policial aos crimes cometidos contra mulheres (SANTOS, 2005). Com a primeira delegacia criada no estado de São Paulo, em 1985, para investigar alguns delitos contra a pessoa do sexo feminino, ${ }^{4}$ surgiu a principal política pública de enfrentamento à violência contra mulheres. Inúmeros estudos foram realizados sobre as DEAMs e em diversas perspectivas (MUNIZ, 1996; SOARES, 1999; BRANDÃO, 1998; SANTOS, 2004; 2005; 2010; CNDM, 2001; DEBERT, 2006; GREGORI, 2006; PASINATO, 2006, 2009, 2010; OBSERVE, 2010; 2011; CEPIA, 2013), não sendo necessário reproduzi-los.

A ideia original era de que o atendimento prestado por policiais do sexo feminino devidamente capacitadas seria mais solidário e respeitoso do que o prestado por policiais homens (SANTOS, 2004; PASINATO; SANTOS, 2008; CNDM, 2001). Desde então, o número de delegacias ampliou-se consideravelmente. $\mathrm{O}$ avanço no número de DEAMs foi registrado pela CPMI. Em 1992, o Brasil possuía 125 delegacias e, em 2012, o número passou para 432, um aumento equivalente a 345,6\%. (BRASIL, 2013, p. 48). Por um lado, esse crescimento reflete o esforço da SPM/PR em ampliar o número de delegacias, por outro, revela o foco privilegiado no sistema de justiça criminal (PASINATO, 2010; 2015).

No entanto, conforme observou a CPMI, não apenas o número de delegacias é insuficiente como a capacitação dos servidores e servidoras é deficitária e não raro o tratamento que as mulheres recebem não é aquele (solidário e respeitoso) que esteve no fundamento de sua criação (OBSERVE, 2011; CEPIA, 2013; PASINATO, 2011; TAVARES, 2015), revelando o despreparo para o atendimento humanizado e a escuta (TAVARES, 2015). 
Além disso, as delegacias da mulher, assim como as demais delegacias de polícia, sofrem com a falta de estrutura, poucos recursos humanos e materiais, e com raras exceções (BRASIL, 2013; OBSERVE, 2011; PASINATO, 2015), atendem o estabelecido na Norma Técnica das DEAMs. Nos 17 estados visitados e em 19 diligências realizadas, a CPMI constatou a situação de abandono e de pouca importância das DEAMs, a falta de investimentos na segurança pública, a precariedade material e os escassos recursos humanos (BRASIL, 2013; OBSERVE, 2011; PASINATO, 2015; SANTOS, 2015). Além disso, a articulação com os outros serviços da rede não é uma política institucional e permanente, dependendo, em muitos casos, da atuação individual de servidores ou servidoras (BRASIL, 2013; OBSERVE, 2011; PASINATO, 2015; SANTOS, 2015).

Ademais, nos estados onde há comunidades indígenas, pomeranas e quilombolas, dentre outras, a CPMI verificou a dificuldade dessas mulheres em acessar à rede. As DEAMs, por exemplo, não possuem profissionais que possam traduzir as demandas das mulheres indígenas, pomeranas ou quilombolas feitas na língua de origem. A dificuldade de acesso desses grupos específicos de mulheres é indicador de negação à justiça na sua dimensão de acessibilidade (ONU, 2015) e favorece a revitimização das mulheres (MADSEN; ABREU, 2014).

\section{i. 2 CASAS-Abrigo}

Até 2003, ao lado das Delegacias da Mulher, as casas-abrigo constituíram-se na principal política pública de enfrentamento à violência contra as mulheres (BRASIL, 2011a; SANTOS, 2015; PASINATO, 2015), com o objetivo de oferecer segurança para as mulheres em risco de morte ou grave ameaça.

$\mathrm{O}$ abrigamento é definido pela SPM/PR como uma série de serviços que incluem programas e benefícios de acolhimento provisório destinados a mulheres em situação de violência (violência doméstica e familiar contra a mulher, tráfico de mulheres etc.) que se encontrem sob ameaça e que necessitem de proteção em ambiente acolhedor e seguro. Nesse sentido:

O abrigamento não se refere somente aos serviços propriamente ditos (albergues, casas-abrigo, casas-de-passagem, casas de acolhimento provisório de curta duração etc.), mas também inclui outras medidas de acolhimento que podem constituir-se em programas e benefícios (benefício eventual para os casos de vulnerabilidade temporária) que assegurem o bem-estar físico, psicológico e social das mulheres em situação de violência, assim como sua segurança pessoal e familiar. (BRASIL, 2011, p. 15)

No entanto, essa nova diretriz de abrigamento ainda não é uma realidade em todo o País. A CPMI ao visitar casas-abrigo em três capitais ${ }^{5}$ encontrou um reduzido 
número de mulheres abrigadas, o que parece indicar que essa forma de abrigamento está em declínio. Entretanto, isso não significa dizer que a violência contra as mulheres esteja decrescendo, o que seria um aspecto positivo, mas pode indicar que as mulheres não estão buscando o serviço oferecido ou desconhecem sua existência ou, ainda, não são a ele encaminhadas (BRASIL, 2013; OBSERVE, 2011; PASINATO, 2015; SANTOS, 2015). No entanto, a hipótese mais provável é que as casas-abrigos, da forma como ainda se estruturam, não atendem mais às necessidades das mulheres. A lógica disciplinante que vigora nas casas não rompe com a noção de confinamento e disciplina dos corpos das mulheres. Relatos de mulheres indicam que se trata de um espaço de violência, pois elas se sentem presas em vez do agressor (TAVARES, 2015, p. 557). Além disso, o afastamento, mesmo que temporário, dos vínculos familiares, de trabalho, escola etc. contribui para que as mulheres prefiram correr risco de morte a ficarem abrigadas. Tampouco contribuem para a autonomia das mulheres, pois os poucos cursos de capacitação oferecidos não conseguem romper a lógica do senso comum e resumem-se aos tradicionais artesanato, manicure e outros que pouco contribuem para a inserção autônoma das mulheres no mercado de trabalho (BRASIL, 2013), reforçando os estereótipos de gênero. Pouquíssimas casas promovem capacitação para inclusão digital ou uma formação profissional que seja, de fato, economicamente rentável ou competitiva (BRASIL, 2013). As casas-abrigo foram (e talvez ainda sejam) espaços importantes para mulheres em risco. No entanto, sua manutenção parece vincular-se a uma ideia de risco não mais compartilhada pelas usuárias. A nova demanda de mulheres ameaçadas pelo tráfico revela uma mudança no perfil das usuárias, problema que grande parte das gestoras e profissionais não está preparada para atender.

\section{3 Centros de referência}

Os centros de referência passaram a integrar a política de enfrentamento à violência contra as mulheres a partir de 2003, quando foi criada a SPM/PR.

Assim como observado com as casas-abrigo, os centros de referência especializados para atendimento às mulheres são poucos e sua grande maioria localiza-se nas capitais (BRASIL, 2013). Os problemas são comuns às demais instituições, como em alguns ausência de profissionais, enquanto outros eram pouco procurados ou raramente recomendados pelas demais instituições (BRASIL, 2013). Em alguns lugares, o centro estava praticamente ao lado da DEAM, no entanto, um número reduzido de mulheres era encaminhado ao local.

Fato que chama a atenção é que os centros que acolhem, além da violência doméstica e familiar, também a violência racial, lesbofobia, contra homossexuais, registraram um elevado número de casos, especialmente de violência homofóbica. Por certo, quanto mais acolhedor, mais registros. No entanto, merece ser mais bem analisada a crescente visibilidade da violência homofóbica comparativamente à violência 
racial, indicando a persistência invisível do racismo institucional (MADSEN; ABREU, 2014).

\section{I.4 JUIZAdOS ESPECIALIZADOS DE VIOLÊNCIA DOMÉSTICA E FAMILIAR}

O reduzido número de juizados, apenas 66, é outro empecilho à plena aplicação da Lei Maria da Penha (BRASIL, 2013, p. 52). Assim como a maioria dos serviços, localiza-se nas capitais (OBSERVE, 2010; PASINATO, 2011), não tem equipe multidisciplinar adequada e completa, não possui servidores em número suficiente e tem excesso de processos em tramitação, levando a prescrição de muitos feitos (BRASIL, 2013, p. 52).

Embora a Lei Maria da Penha estabeleça a competência civil e criminal para os Juizados Especializados de Violência Doméstica e Familiar, a grande maioria deles atua apenas na esfera criminal, obrigando as mulheres a ingressarem nas varas de família para os procedimentos de natureza não criminal. Com isso, inviabiliza-se a dupla jurisdição e rompe-se com a lógica da Lei Maria da Penha de evitar a peregrinação das mulheres em busca de justiça. A alegação para o descumprimento da lei é a de que os juizados e varas não possuem estrutura para atender a essa dupla demanda, já que as medidas protetivas são inúmeras e abarrotam os juizados (BRASIL, 2013).

Entretanto, a lei estabeleceu a competência híbrida (civil e criminal) para evitar que as mulheres tivessem de percorrer duas instâncias judiciais diferentes quando a origem do problema é a mesma: a violência doméstica e familiar (CAMPOS; CARVALHO, 2011). Sabe-se que, com a criação da Lei Maria da Penha, a violência doméstica, antes julgada nos juizados especiais criminais, nas varas criminais ou de família, deslocou-se para os Juizados ou Varas especializadas de violência doméstica. Isso, por um lado, diminuiu substancialmente a atividade processual e cartorária dessas varas, e, por outro, sobrecarregou os juizados especializados. No entanto, mesmo com a diminuição dos processos nas varas criminais e de família em decorrência de seu deslocamento para os Juizados Especializados de Violência Doméstica, o Poder Judiciário não se adequou a esta nova realidade, mantendo varas criminais comuns com pouca movimentação e Juizados Especializados sobrecarregados.

Observa-se, portanto, uma lógica invertida da prestação jurisdicional. É como se a realidade da violência devesse adequar-se ao Poder Judiciário e não este à realidade social. A prestação jurisdicional apresenta-se não como um dever do estado e um direito das mulheres, mas como um “direito capenga”, um "meio direito". Assim, as mulheres têm direito, mas "nem tanto". (CAMPOS, 2015, p. 524). A ausência de preferência na criação dos Juizados ou Varas Especializadas pelos Tribunais de Justiça revela que a violência doméstica e familiar não possui relevância para merecer prioridade orçamentária.

Por sua vez, a violência doméstica praticada contra as mulheres indígenas e a dificuldade de a lei "ingressar" nas aldeias introduzem novos problemas relacionados 
à sua aplicação. O fato de as aldeias estarem sob a jurisdição federal e a cobrança das indígenas que querem ver a lei aplicada à violência por elas sofrida ${ }^{6}$ são elementos de tensão na aplicação e abrangência da lei.

Igualmente, a aplicação da lei para casais de lésbicas tem sido pouco visibilizada, talvez pelo reduzido número de casos que chegam ao Judiciário ou pelo despreparo dos operadores do direito em lidar com essa violência.

\section{5 Departamentos Médico-Legais (DML/IML)}

O serviço de perícia médica é uma atividade realizada pelos departamentos médicolegais (DML) ou pelos institutos médico-legais (IML). Estes serviços são essenciais para a comprovação de muitos crimes e para a coleta da prova nos crimes de lesões corporais, estupro e homicídios. A Lei Maria da Penha, no art. 35, III, expressamente estabelece a obrigatoriedade de criação de serviços médico-legais especializados para o atendimento às mulheres.

No entanto, a realidade desses serviços está longe de ser ideal. Os IMLs visitados pela CPMI encontravam-se em péssimas condições físicas, materiais e deficientes em recursos humanos. Alguns sequer deveriam estar em funcionamento tamanha a precariedade. ${ }^{7}$ (BRASIL, 2013, p. 51). Além disso, as poucas unidades nos estados concentram-se nas capitais, adicionando outro obstáculo ao acesso à justiça. Em alguns estados, as mulheres têm de viajar a outros municípios para realizarem o exame de corpo de delito. ${ }^{8}$ (BRASIL, 2013). Em razão da distância e da falta de recursos, muitas mulheres deixam de realizar o exame de corpo de delito e, com isso, o inquérito policial e a obtenção da prova tendem a ficar comprometidos e serem arquivados por prescrição.

\section{I.6 Serviços de Abortamento Legal}

$\mathrm{O}$ atendimento das mulheres nos serviços de abortamento legal visa garantir os direitos sexuais e reprodutivos e, embora esteja regulamentado pelo Ministério da Saúde, mostrou-se quase inexistente.

O abortamento legal está diretamente ligado aos permissivos penais (estupro e para salvar a vida da gestante) e, em casos de anencefalia, situações em que sua realização não é penalizada, sendo normatizadas pelo Ministério da Saúde. A Norma Técnica de Atenção Humanizada ao Abortamento parte do reconhecimento de que abortamentos praticados em condições inseguras são causa de morte materna, razão pela qual as mulheres que procuram os serviços devem ser tratadas com dignidade (BRASIL, 2005 , p. 5). Nesse sentido, o acolhimento e a orientação adequada são deveres dos profissionais de saúde e direito das mulheres.

Apesar da normatização existente, a CPMI diagnosticou que os estados tiveram muita dificuldade em informar quantos abortamentos haviam realizado do período investigado. Mesmo aqueles que responderam dizendo que realizam o procedimento, não informaram quantos foram realizados. A invisibilidade decorre não apenas da ausên- 
cia de informações sobre esses serviços, mas também da omissão dos próprios serviços, que não divulgam sua existência, ocultando a informação e, consequentemente, dificultando o acesso às mulheres que dele necessitam. Conforme vários estudos apontam (OMS, ONU, 2011), a ausência de serviços de abortamento legal coloca em risco a vida das mulheres porque leva à procura por serviços inseguros. A descriminalização do aborto e a criação e ampliação dos serviços de abortamento legal têm sido recomendações constantes dos mecanismos de direitos humanos das mulheres (ONU, 2011; CEDAW, 2012).

\section{I.7 NOTIFICAÇÃO COMPULSÓRIA DA VIOLÊNCIA DOMÉSTICA E SEXUAL}

A notificação compulsória da violência doméstica e sexual pelos serviços de saúde foi instituída pela Lei n. 10.778/2003 e obriga a todo o serviço de saúde público ou privado a notificar toda e qualquer violência sofrida pelas mulheres. Apesar da importância e obrigatoriedade da notificação, esta ainda é baixa no Brasil, especialmente no interior, onde alguns municípios não haviam notificado um caso sequer. (BRASIL, 2013). A pouca compreensão dos profissionais sobre a importância da notificação dificulta não apenas dimensionar a magnitude da violência, mas também desenvolver as políticas de saúde, prevenção e assistência (BRASIL, 2013). O aumento da notificação está diretamente relacionado à capacitação dos profissionais de saúde, o que destaca a importância das ações que vêm sendo promovidas pelo Ministério da Saúde, com certa regularidade e em parceria com as secretarias de saúde estaduais e municipais (BRASIL, 2015).

\section{I.8 A DIFICULDADE DA INTERIORIZAÇÃO DAS POLÍTICAS}

Não há dúvida de que a dimensão e a diversidade geográfica do Brasil são fatores que dificultam a interiorização das políticas públicas. No entanto, é a concentração de recursos nas capitais e regiões metropolitanas, por um lado, e a ausência de políticas específicas, por outro, o que invisibiliza mulheres ribeirinhas, indígenas, rurais, pomeranas, negras. Questões simples como a presença de um intérprete para mulheres indígenas, pomeranas ou comunidades quilombolas, nos estados onde se concentram, demonstra também a invisibilidade dessas mulheres.

A invisibilidade também se dá pela dificuldade de acesso aos serviços, embora ações venham sendo tomadas pela SPM/PR, a exemplo das unidades móveis. ${ }^{9}$ Dar visibilidade às diversas necessidades das mulheres é um enorme desafio, especialmente em um país como o Brasil, cuja amplitude e diversidade geográfica e regional agravam a situação, sob pena de se transformar a diversidade em revitimização e exclusão.

\section{CONCLUSÃO: SUPERANDO OS OBSTÁCULOS NA APLICAÇÃO DA LEI}

Como mencionado no início, este artigo pretendeu sistematizar os principais obstáculos apontados pela CPMI para a implementação da dimensão da assistência às mulheres 
em situação de violência caracterizada pela rede especializada de atendimento às mulheres prevista na Lei Maria da Penha.

A perspectiva da complexidade da violência doméstica e familiar assumida pela referida lei fez com que apostasse em tratamento integral, mas dependente de ações articuladas entre as diversas instituições públicas federais, estaduais e municipais e com as organizações da sociedade civil, isto é, da rede de atendimento. Uma das constatações, conforme diagnosticado pela CPMI e outros estudos, é o fato de que as redes são diversificadas e, e em geral, mais pessoalizadas que institucionalizadas. A sua existência é mais visível nas capitais, onde também apresentou grau maior de desarticulação ou pouca comunicação. Os serviços também sofrem com a precária estrutura física e ausência de profissionais, a exemplo das DEAMs e Centros de Referência. As casas-abrigo tornaram-se espaços vazios, lugares mais identificados com violência do que proteção e despreparados para a nova demanda da violência originada do tráfico.

A dificuldade de acesso à rede é um obstáculo para o acesso à justiça para mulheres negras, ribeirinhas, pomeranas, da mata, indígenas etc. Sua superação depende sem dúvida de mais recursos, mas também do esforço e aposta política dos agentes estatais na sua implementação.

O reforço na dimensão preventiva e assistencial caracterizada pela rede é uma aposta no enfraquecimento da perspectiva repressiva que por anos norteou as políticas públicas de enfrentamento à violência contra mulheres. A Lei Maria da Penha fez essa aposta. Resta saber se os poderes públicos estão com ela comprometidos.

\section{NOTAS}

1 A autora do artigo assessorou a CPMI, especialmente a Relatora, Senadora Ana Rita. Durante o seu trabalho, a CPMI conversou com especialistas, visitou os dez estados com as maiores taxas de homicídios de mulheres e outros sete por solicitação das parlamentares; realizou audiências públicas, ouviu o movimento de mulheres, visitou a rede especializada e analisou os documentos enviados pelos estados.

2 No Título III estão previstas as medidas de assistência à mulher em situação de violência e no Capítulo I, as medidas de prevenção $\left(\operatorname{art.} 8^{\circ}\right)$ e de assistência $\left(\operatorname{art.} 9^{\circ}\right)$.

3 Utiliza-se aqui o conceito de rede formulado no documento Rede de Enfrentamento à Violência contra a Mulher. Conforme o documento, a "o conceito de rede de enfrentamento à violência contra as mulheres diz respeito à atuação articulada entre as instituições/serviços governamentais, não governamentais e a comunidade, visando ao desenvolvimento de estratégias efetivas de prevenção e de políticas que garantam o empoderamento e construção 
da autonomia das mulheres, os seus direitos humanos, a responsabilização dos agressores e a assistência qualificada às mulheres em situação de violência" (BRASIL, 2011, p. 13).

4 O Decreto n. 23.769, de 6 de agosto de 1985, que criou a primeira delegacia da mulher, estabeleceu que esta deveria investigar determinados "delitos contra a pessoa do sexo feminino", tais como ameaças, lesões corporais, adultério, constrangimento ilegal, atentado violento ao pudor. A Delegacia de São Paulo foi criada como Delegacia dos Direitos da Mulher (DDMs).

5 A visita foi realizada nas casas-abrigo de Maceió/AL, Boa Vista/RR e João Pessoa/PB.

6 Durante a visita da CPMI ao estado de Mato Grosso do Sul e em reunião com as mulheres indígenas, estas relataram a violência sofrida e a dificuldade de aplicação da Lei Maria da Penha.

7 O DML de Maceió/AL estava em condições precaríssimas.

8 Fato observado no estado de Goiás.

9 Unidades Móveis para atendimento a mulheres em situação de violência no campo e na floresta. Conforme o site disponível em <www.spm.gov.br>.

\section{REFERÊNCIAS BIBLIOGRÁFICAS}

BARSTED, Leila. Lei Maria da Penha: uma experiência bem-sucedida de advocacy feminista. In: CAMPOS, Carmen Hein de (org.). Lei Maria da Penha comentada na perspectiva jurídico-feminista. Rio de Janeiro: Lumen Juris, 2011.

BRANDÃO, Elaine Reis. Violência conjugal e o recurso feminino à polícia. In: BRUSCHINI, Cristina; HOLLANDA, Heloísa Buarque (org.). Horizontes plurais: novos estudos de gênero no Brasil. São Paulo: Editora 34, 1998.

BRASIL. Diretrizes Nacionais para o abrigamento de mulheres em situação de risco e violência. Brasília: Secretaria Nacional de Enfrentamento à Violência contra as Mulheres Secretaria de Políticas, 2011a. Disponível em: <http://www.spm.gov.br/sobre/publicacoes/publicacoes/2011/abrigamento>. Acesso em: 4 mai. 2015.

. Pacto Nacional de Enfrentamento à Violência contra a Mulher. Brasília: Secretaria Nacional de Enfrentamento à Violência contra as Mulheres Secretaria de Políticas da Presidência da República, 2011 b. Disponível em: <http://www.spm.gov.br/sobre/publicacoes/publicacoes/2011/pacto-nacional>. Acesso em: 4 mai. 2015.

. Rede de Enfrentamento à Violência contra as Mulheres. Brasília: Secretaria Nacional de Enfrentamento à Violência contra as Mulheres. Brasília: Secretaria de Políticas para as Mulheres da Presidência da República, 2011c. Disponível em: <http://www.spm.gov.br/sobre/publicacoes/publicacoes/ $2011 /$ rede-de-enfrentamento>. Acesso em: 4 mai. 2015.

Norma Técnica de Padronização das DEAMs. Brasília: Secretaria de Política para as Mulheres, 2010. Disponível em: <http://www.spm.gov.br/lei-maria-da-penha/lei-maria-da-penha/norma-tecnica-depadronizacao-das-deams-.pdf>. Acesso em: 22 mai. 2015.

Relatório final. Comissão Parlamentar Mista de Inquérito. Brasília: Senado Federal, 2013.

Norma Técnica Atenção Humanizada ao Abortamento. Brasília: Ministério da Saúde. Disponível em: <http://bvsms.saude.gov.br/bvs/publicacoes/atencao_humanizada.pdf>. Acesso em: 11 mai. 2015. . Relatório de Auditoria Operacional. Ações de enfrentamento à violência doméstica e familiar contra a mulher. Brasília: Tribunal de Contas da União, 2012.

CAMPOS, Carmen Hein de; CARVALHO, Salo. Tensões atuais entre a criminologia feminista e a criminologia crítica: a experiência brasileira. In: CAMPOS, Carmen Hein de (Org.). Lei Maria da Penha Comentada em uma perspectiva jurídico-feminista. Rio de Janeiro: Lumen Juris, 2011. 
CAMPOS, Carmen Hein de. A CPMI da violência contra a mulher e a implementação da Lei Maria da Penha. Revista Estudos Feministas. n. 23, v. 2. Florianópolis, 2015, p.519-531.

CEPIA - Cidadania, Estudos, Pesquisa, Informação e Ação. Violência contra a mulher e acesso à justiça. Estudo comparativo sobre a aplicação da Lei Maria da Penha em cinco capitais. Relatório final. Rio de Janeiro: CEPIA/Ford, 2013.

CNDM - Conselho Nacional dos Direitos da Mulher. Pesquisa nacional sobre as condições de funcionamento das delegacias especializadas no atendimento às mulheres. Relatório final. Brasília: Conselho Nacional dos Direitos da Mulher, 2001.

DEBERT, Guita Grin. As Delegacias de Defesa da Mulher: judicialização das relações sociais ou politização da justiça?. In: CORRÊA, Mariza; SOUZA; Érica Renata de (Org.). Vida em família: uma perspectiva comparativa sobre "crimes de honra”. Campinas: Pagu-Núcleo de Estudos de Gênero/Universidade Estadual de Campinas, 2006.

GREGORI, Maria Filomena. Delegacias de Defesa da Mulher de São Paulo: paradoxos e paralelismos. In: DEBERT, Guita Grin; GREGORI, Maria Filomena; PISCITELLI, Adriana (Org.). Gênero e distribuição da justiça: as Delegacias de Defesa da Mulher e a construção das diferenças. Campinas: Pagu/Núcleo de Estudos de Gênero, Unicamp, 2006.

MADSEN, Nina; ABREU, Masra de. Tolerância institucional à violência contra as mulheres. Brasília: Cfemea, 2014. MUNIZ, Jacqueline. Os direitos dos outros e os outros direitos: um estudo sobre a negociação de conflitos nas DEAMs/RJ. In: SOARES, Luiz Eduardo (Org.). Violência e política no Rio de Janeiro. Rio de Janeiro: ISER/Relume Dumará, 1996.

OBSERVE. Observatório pela Aplicação da Lei Maria da Penha. Condições para aplicação da Lei $n$. 11.340/2006 (Lei Maria da Penha) nas Delegacias Especializadas de Atendimento à Mulher (DEAMs) e nos Juizados de Violência Doméstica e Familiar nas capitais e no Distrito Federal. Salvador: Observe, 2010. Disponível em: <http://www.spm.gov.br/subsecretaria-de-enfrentamento-a-violencia-contra-as-mulheres/leimaria-dapenha/20110107-relatorio-final-2010.pdf>. Acesso em: 24 out. 2015.

. Identificando entraves na articulação dos serviços de atendimento às mulheres vítimas de violência doméstica e familiar em cinco capitais. Projeto Observe/Unifem. Relatório Final, 2011.

PASINATO, Wânia. Avanços e obstáculos na implementação da Lei n. 11.340/2006. In: CAMPOS, Carmen Hein de (Org.). Lei Maria da Penha comentada em uma perspectiva jurídico-feminista. Rio de Janeiro: Lumen Juris, 2011.

Oito anos de Lei Maria da Penha. Entre avanços, obstáculos e desafios. Estudos Feministas, Florianópolis, v. 23, n. 2, maio 2015. Disponível em: <https://periodicos.ufsc.br/index.php/ref/article/ view/38874/29353>. Acesso em: 26 out. 2015.

. Atendimento às mulheres em situação de violência em Belo Horizonte. In: LEOCÁDIO, Elcylene; LIBARDONI, Marlene (Org.). O desafio de construir redes de atenção às mulheres em situação de violência. Brasília: Agende, 2006.

- Estudo de caso. Juizados Especiais de Violência Doméstica e Familiar contra a Mulher e a Rede de Serviços para Atendimento de Mulheres em Situação de Violência em Cuiabá, Mato Grosso. Relatório final. São Paulo: Observe, set. 2009.

SANTOS, Cecília MacDowell. Delegacias da Mulher em São Paulo: Percursos e percalços. In: REDE SOCIAL DE JUSTIÇA E DiREITOS HumAnOS (Org.). Relatório de Direitos Humanos no Brasil. Rio de Janeiro: Parma, 2001.

Curto-circuito, falta de linha ou na linha? redes de enfrentamento à violência contra mulheres em São Paulo. Estudos Feministas, Florianópolis, v. 23, n. 2, maio 2015. Disponível em: <https://periodicos.ufsc.br/ index.php/ref/article/view/38878>. Acesso em: 26 out. 2015.

SOARES, Bárbara. Delegacia de atendimento à mulher: questão de gênero, número e grau. In: SOARES, L. E. et alli Violência e política no Rio de Janeiro. Rio de Janeiro, Relume Dumará/ISER, 1999.

TAVARES, Márcia Santana. Roda de conversa entre mulheres: denúncias sobre a Lei Maria da Penha e descrença na justiça. Estudos Feministas, Florianópolis, v. 23, n. 2, maio 2015. Disponível em: <https://periodicos.ufsc.br/ index.php/ref/article/view/38875/29354>. Acesso em: 26 out. 2015.

WAISELFISZ, Julio Jacobo. Mapa da violência 2012: Atualização Homicídios de Mulheres no Brasil.

Disponível em: <http://www.mapadaviolencia.org.br/pdf2012/MapaViolencia2012_atual_mulheres.pdf>. Acesso em 10 mai. 2015.

\section{Sites consultados}

Instituto Brasileiro de Geografia e Estatística (IBGE). Disponível em: http://www.ibge.gov.br/home/estatistica/ economia/perfilmunic/2013/default.shtm>. Acesso em: 4 mai. 2015. 
Mapa da violência. Disponível em: <www.mapadaviolencia.org.br>. Acesso em: 4 mai. 2015.

Secretaria de Políticas para as Mulheres da Presidência da República. Disponível em: <www.spm.gov.br>. Acesso em: 4 mai. 2015.

\section{Carmen Hein de Campos}

Vila Velha - ES - Brasil

carmen.camposlauvv.br
Professora do Programa de Pós-Graduação em Segurança Pública da Universidade Vila Velha.

Doutora em CIÊnCias Criminais pela Pontifícia Universidade Católica do Rio Grande do Sul. Mestre em Direito pela Universidade Federal de Santa Catarina.

Mestre em Direito pela Universidade de Toronto (Programa Direitos Sexuais e Reprodutivos). 
